\section{CT to the rescue in benign, symmetrical mediastinal lipomatosis}

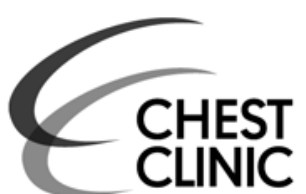

A 34-year-old woman presented to the chest physician with progressively increasing shortness of breath. She was non-diabetic, non-hypertensive, non-obese without any other co-morbid illnesses. There was no history of prolonged drug intake of any sort. Other associated diseases like Cushing's syndrome were excluded. A chest radiograph (postero-anterior view) revealed a veil-like opacity in the mediastinum obscuring the cardiac borders (figure 1). To further evaluate the nature of mediastinal pathology, a chest CT was done. The CT showed gross, bilaterally symmetrical masses of adipose tissue in the mediastinum causing segmental atelectasis of the lungs (figure 2). The

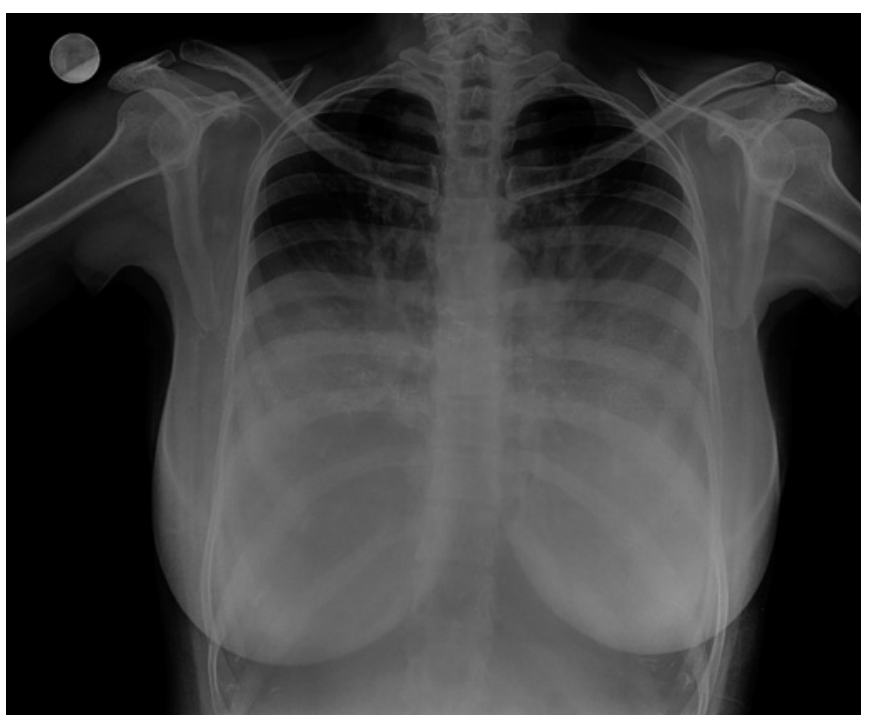

Figure 1 Chest radiograph (posteroanterior view) showing extensive veil-like mediastinal widening obscuring the cardiac borders.
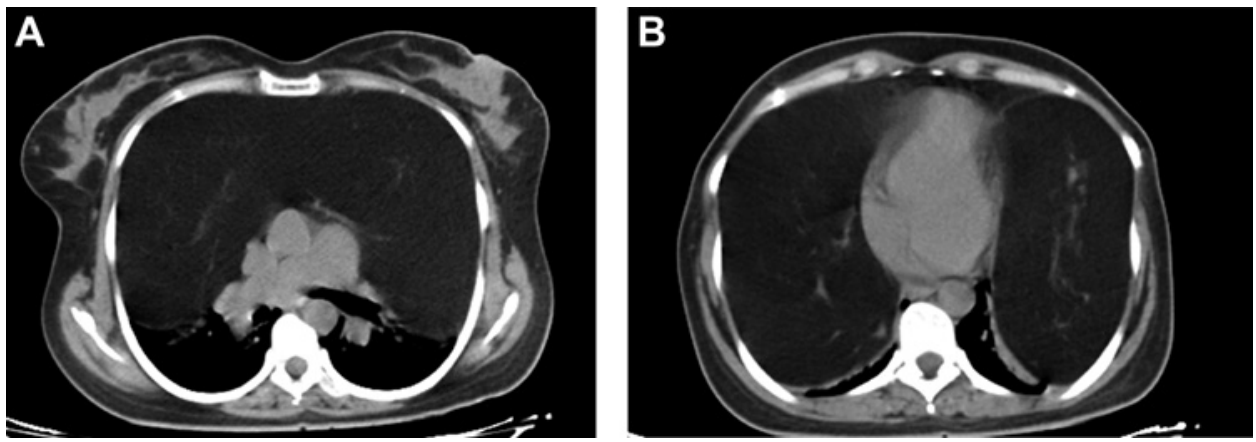

Figure 2 ( $A, B)$ Axial non-contrast CT showing fatty symmetrical masses in the mediastinum.

Published Online First 22 May 2012 fatty tissue extended from the superior mediastinum into the anterior mediastinum up to the diaphragm. It exhibited a range of attenuation values from -155 to -110 Hounsfield units. The diagnosis of extensive mediastinal lipomatosis was established, which was proven by a biopsy from the mass. In this condition, mature adipose tissue is deposited symmetrically in the mediastinum. ${ }^{1}$ The mediastinal lipomatosis in this case is idiopathic. ${ }^{2}$

\section{Learning points}

- Gross symmetric mediastinal widening in the absence of trauma can be caused by benign entities like lipomatosis.

- CT and MRI are usually sufficient to establish a diagnosis.

\section{Shivali Kashikar, Amol Jayant Gulkari, Pooja Kailash Singhania}

Department of Radiodiagnosis, Jawaharlal Nehru Medical College, Sawangi Meghe, Wardha, India

Correspondence to Dr Shivali V Kashikar, Department of Radiodiagnosis, Jawaharlal Nehru Medical College, Sawangi Meghe, Wardha 442005, India; shivalikashikar@gmail.com

Contributors SK, AJG and PKS have contributed equally to this case report.

Competing interests None.

Patient consent Obtained.

Ethics approval The ethics approval was provided by institutional ethics committeee. Provenance and peer review Not commissioned; internally peer reviewed.

Received 16 March 2012

Accepted 22 March 2012

Thorax 2012;67:758. doi:10.1136/thoraxjnl-2012-201911

\section{REFERENCES}

1. Rajani R, Gandhi S, Brum RL. Mediastinal Mayhem. BMJ Case Reports 2009. Published Online First 2 Feb 2009. doi:10.1136/bcr.06.2008.0194

2. Pungavkar S, Shah J, Patkar D, et al. Isolated symmetrical mediastinal lipomatosis $J$ Assoc Physicians India 2001:49:1026-8. 